\title{
EFECTO DEL MANEJO ORGÁNICO Y CONVENCIONAL SOBRE PROPIEDADES BIOQUÍMICAS DE UN ANDISOL Y EL CULTIVO DE PAPA EN INVERNADERO ${ }^{1}$
}

\author{
Stephanie Marín*, Floria Bertsch ${ }^{*}$, Leida Castro $^{2 / *}$ \\ Palabras clave: Agricultura orgánica; fertilización convencional; fertilización orgánica; solubilizadores de P; \\ Andisol; efecto residual; Finca Orgánica Guadalupe. \\ Keywords: Organic agriculture; conventional fertilizer; organic fertilizer; solubilizers P; Andisol; residual \\ effect; Organic Farm Guadalupe.
}

Recibido: $27 / 09 / 16$

RESUMEN

Se determinaron características bioquímicas de un Andisol de Zarcero, sometido por más de 20 años, al manejo orgánico y al convencional. Posteriormente se evaluó en ambos suelos el rendimiento de la papa en condiciones de invernadero, bajo los siguientes tratamientos: fertilización convencional, fertilización orgánica, fertilización convencional más solubilizadores de $\mathrm{P}$ y fertilización orgánica más solubilizadores de $\mathrm{P}$ y un testigo. Concluido el ciclo de la papa, se cultivó maíz para evaluar el efecto residual de los diferentes tipos de fertilización. El suelo orgánico presentó $54 \%$ más C orgánico, la acidez fue muy baja $\left(0,16 \mathrm{cmol}(+) . \mathrm{l}^{-1}\right)$ y el $\mathrm{pH}$ alcanzó la neutralidad $(6,3)$, mientras que para el suelo convencional los valores fueron de $1,4 \mathrm{cmol}(+) .1^{-1}$ y 5. Los contenidos de $\mathrm{Ca}$ y $\mathrm{Mg}$ en el suelo orgánico cuadriplicaron los valores del suelo convencional, por lo que la CEC se duplicó. El suelo convencional presentó desbalances en todas las relaciones, mientras que el suelo orgánico en la relación $\mathrm{Ca} / \mathrm{Mg}$. Los valores de $\mathrm{C}$ y $\mathrm{N}$ totales fueron inferiores en el suelo convencional, y la relación $\mathrm{C} / \mathrm{N}$ fue similar. El $\mathrm{P}$ en las 2 condiciones fue alto, en el suelo convencional se relacionó

1 Este trabajo forma parte de la tesis de grado de la primera autora.

2 Autora para correspondencia. Correo electrónico: leida.castro@ucr.ac.cr
Aceptado: $31 / 05 / 17$

\section{ABSTRACT}

Biochemical characterization of an organic and conventional managed Andisol, and its evaluation by the response of greenhouse-grown potato. Biochemical characteristics of an Andisol of Zarcero, subjected for more than 20 years to conventional and organic management, were determined. Then behavior of both soils was evaluated by studying the yield of potato crop in greenhouse conditions, under the following treatments: conventional fertilization, organic fertilization, conventional fertilization with $\mathrm{P}$ solubilizers, organic fertilization with $\mathrm{P}$ solubilizers and no fertilization. Once the potato cycle was completed, maize was grown in order to evaluate the residual effect of the different types of fertilization. The organic soil showed $54 \%$ more organic $\mathrm{C}$, its acidity was very low $\left(0.16 \mathrm{cmol}(+) . \mathrm{l}^{-1}\right)$ and the $\mathrm{pH}$ reached neutrality (6.3); meanwhile, the values on the conventional soil were $1.4 \mathrm{cmol}(+) . \mathrm{l}^{-1}$ and 5 , respectively. The contents of $\mathrm{Ca}$ and $\mathrm{Mg}$ in the organic soil were four times higher than in the conventional soil, so the CEC was doubled. The conventional soil presented unbalances in all the rations, while the organic soil in the $\mathrm{Ca} / \mathrm{Mg}$ ratio. Total $\mathrm{C}$ and

Universidad de Costa Rica, Centro de Investigaciones Agronómicas, Costa Rica. 
con las fertilizaciones químicas, mientras que en el suelo orgánico a las fuentes minerales y orgánicas. Los valores de $\mathrm{Cu}, \mathrm{Fe}$ y $\mathrm{Mn}$ fueron menores en el suelo orgánico. La cantidad de UFC.gr ${ }^{-1}$ de actinomicetes y bacterias fue menor en uno y 2 órdenes de magnitud en el suelo convencional, mientras la tasa de respiración fue mayor. En el suelo con manejo convencional, la fertilización convencional más solubilizadores de $\mathrm{P}$ generó el mayor rendimiento de tubérculos. En el suelo con manejo orgánico, la fertilización convencional y la orgánica presentaron el mayor rendimiento sin diferencia significativa entre ellos. Además, el suelo convencional con fertilización convencional y el suelo orgánico con fertilización orgánica obtuvieron rendimientos similares. La fertilización convencional ocasionó una mayor residualidad en ambos suelos.

\section{INTRODUCCIÓN}

La calidad de un suelo agrícola, es una medida de su capacidad para sostener la productividad de las cosechas, mientras se preserva la calidad ambiental (Bending et al. 2004). Las Naciones Unidas reconocen la agricultura orgánica, biológica o ecológica, como un sistema agrícola innovador que combina métodos tradicionales con tecnologías modernas y que representa una opción en la búsqueda de sistemas sostenibles, que permitan la producción de alimentos y la conservación de los ecosistemas. Sin embargo, la misma es aun considerada por muchos críticos como un enfoque ineficiente en la búsqueda de la seguridad alimentaria a nivel global. Aun así, el número de fincas orgánicas, la extensión total de las mismas y el mercado se
$\mathrm{N}$ values were lower in the conventional soil, and the $\mathrm{C} / \mathrm{N}$ ratio was similar in both systems. $\mathrm{P}$ was high in both systems; in the conventional soil, the high value was related to the application of chemical fertilizers, while in the organic soil, the $\mathrm{P}$ content was related to mineral and organic sources. The $\mathrm{Cu}, \mathrm{Fe}$ and $\mathrm{Mn}$ values were lower in the organic soil. The amount of UFC.gr-1 of actinomycetes and bacteria in the conventional soil were lower in one and 2 orders of magnitude respectively, while soil respiration was higher. The conventional fertilization with $\mathrm{P}$ solubilizers allowed higher tuber yields in the soil with conventional handling. In the organic soil, the higher potato yield were obtained with the conventional and organic fertilization with no significant differences among them. In addition, the conventional fertilization in the conventional soil and the organic fertilization in the organic soil had similar yields. The conventional fertilization caused higher residuality in both soils.

ha incrementado ampliamente a nivel mundial (Reganold y Wachter 2016).

El suelo es la matriz donde se desarrollan los agrosistemas y el manejo que recibe modifica sus características físico-químicas y biológicas, así como su capacidad productiva (Barrios 2007, Méndez y Bertsch 2012, Kibblewhite et al. 2015, Castro et al. 2015). En los sistemas orgánicos, la conservación y mejora de las características físicas, químicas y microbiológicas del suelo es fundamental, por lo que la incorporación de insumos orgánicos (compost, vermicompost, bioles, etc.) es una práctica común que tiene como fin acondicionar el suelo e incorporar biota para optimizar la absorción nutrimental de las plantas, su vigor y sanidad (Gliessman 2002, Monreal 2003).

Por otro lado, en los sistemas convencionales de producción agrícola, la aplicación 
sobredosificada de fertilizantes no ha solucionado los problemas de absorción que tienen cultivos como la papa, y más bien resulta en una inversión innecesaria que conduce a consecuencias adversas para el suelo y el medio ambiente (Rojas y Ortuño 2007, Suárez et al. 2006).

La papa (Solanum tuberosum) es uno de los productos agrícolas más consumidos a nivel mundial. En Costa Rica se consumen aproximadamente 5000 toneladas métricas de papa por mes, lo que lo convierte en un producto base de la alimentación nacional (Babilonia 2011). Se produce principalmente en la provincia de Cartago, en las faldas del volcán Irazú y del volcán Turrialba, la cual contiene el 75,2\% de la producción en Tierra Blanca, Llano Grande, Pacayas y Santa Cruz de Turrialba, mientras que el 24,2\% se desarrolla en Zarcero de Alajuela y en algunas zonas de San José como Dota y Coronado. El rendimiento promedio de la papa a nivel nacional es de 25 toneladas por hectárea en un área de aproximadamente 2233 hectáreas donde trabajan alrededor 1200 productores (SEPSA 2011).

Actualmente, la producción convencional de papa es la más utilizada en el país, a pesar de esto, existe un interés en mejorar las prácticas culturales e integrar medidas para una producción más sostenible con el ambiente. Se pretende racionalizar la inversión en insumos sintéticos sin reducir la calidad en el producto final (Suárez et al. 2006, GFA 2010).

A pesar de ser capaz de producirse en diversas condiciones edafoclimáticas en el país, el cultivo de la papa presenta una limitación en cuanto a la absorción del fósforo (P), debido a la fijación que sufre este elemento en los suelos de origen volcánico (Babilonia 2011, Alvarado et al. 2009). Una opción que podría resultar interesante para mejorar el comportamiento del P en Andisoles, es la aplicación de microorganismos solubilizadores de P (Ferrera y Alarcón 2001).

La aplicación de materiales orgánicos y microorganismos benéficos no ha sido una práctica general en el cultivo del tubérculo en el país, pese a que se han observado resultados favorables en otros países sobre el rendimiento de la papa (Muñoz y Lucero 2008, Hernández 2001) Zamora et al. (2008) y de otros cultivos como banano, palmito y cebolla (Enríquez y Bernal 2008, Fernández et al. 2010, Moreno 1988, Rojas y Ortuño 2007). Además, se ha comprobado que la presencia de materia orgánica y de microorganismos mejora las condiciones químicas, físicas y biológicas del suelo a largo plazo y beneficia la protección y el rendimiento de los cultivos (Ferrera y Alarcón 2001, Angoa 2012, Castro et al. 2015).

Zarcero se caracteriza por la producción orgánica, principalmente de hortalizas. Debido a que en esta zona conviven tanto fincas orgánicas como convencionales, se planteó el objetivo de comparar características químicas y biológicas de un suelo volcánico que ha sido sometido por más de 20 años a la producción de hortalizas orgánicas, con un suelo aledaño dedicado a la producción convencional de hortalizas y posteriormente evaluar la respuesta de la papa en invernadero (cultivo de interés comercial para la producción orgánica de la zona) en los suelos procedentes de ambos manejos, junto con la aplicación de un producto biológico comercial con presencia de 2 microorganismos reconocidos como solubilizadores de P. Adicionalmente, evaluar el efecto residual del tipo de fertilización sobre el crecimiento del maíz.

\section{MATERIALES Y MÉTODOS}

\section{Caracterización de los suelos de ambos manejos}

Los suelos utilizados procedieron de la zona de Zarcero, uno de la Finca Orgánica Guadalupe (certificada orgánica), donde se ha implementado este manejo durante los últimos 20 años, y el otro, de una finca aledaña que ha sido manejada de manera convencional durante ese mismo período.

Se recolectaron aproximadamente $100 \mathrm{~kg}$ de suelo de ambos manejos, de los cuales se tomaron 2 muestras representativas de $500 \mathrm{~g}$ para 
realizar los análisis químicos y microbiológicos correspondientes.

La composición química de los suelos fue determinada de la siguiente manera: $\mathrm{El} \mathrm{pH}$ en agua, la acidez, $\mathrm{Ca}$ y $\mathrm{Mg}$ en $\mathrm{KCl}, \mathrm{P}, \mathrm{K}, \mathrm{Zn}, \mathrm{Fe}$, $\mathrm{Mn}$ y $\mathrm{Cu}$ en Olsen modificado y el $\mathrm{C}$ y $\mathrm{N}$ total por combustión seca en el autoanalizador $\mathrm{C} / \mathrm{N}$. El $\% \mathrm{MO}$ se calculó a partir del \%C total multiplicado por el factor de correlación $(1,43)$ determinado en el LSF/CIA.

En cuanto a las variables biológicas, las poblaciones de solubilizadores de $\mathrm{P}$ se determinaron por medio de la técnica de diluciones seriadas y la determinación del número más probable (NMP) según Osorio y Habte (2001). Las unidades formadoras de colonias (UFC) de bacterias, hongos y actinomicetes se determinaron mediante la técnica de recuentos de microorganismos viables en placas petri y la tasa de respiración por medio del cálculo de la concentración del $\mathrm{CO}_{2}$ producido por día por gramo de suelo (Jenkinson y Powlson 1976), en el Laboratorio de Microbiología Agrícola del CIA/UCR.

\section{Localización y material experimental del ensayo de invernadero}

El ensayo se llevó a cabo en el invernadero del Laboratorio de Suelos y Foliares (LSF) del Centro de Investigaciones Agronómicas (CIA). En el mismo centro se realizaron los análisis químicos y microbiológicos.

Se utilizó semilla de papa pre-básica de la variedad Duran, esta es una variedad amarilla para consumo fresco e industrial (Avilés 2014 Características de la variedad de papa Duran (comunicación, correo electrónico). Cartago,
Costa Rica, Estación Carlos Durán, INTA) y los suelos provenientes de los 2 manejos en estudio.

\section{Diseño experimental y tratamientos}

Se utilizó un diseño estadístico experimental de Bloques Completos al Azar con un arreglo factorial $2 \times 5$, correspondiente al manejo orgánico y al convencional, y 5 tratamientos de fertilización en cada suelo incluyendo los testigos, con 5 repeticiones cada uno, para un total de 50 unidades experimentales.

Los tratamientos se instalaron en potes de 4 litros, donde se sembraron 2 semillas de papa (Moreno 2012).

Los tratamientos aplicados en cada suelo fueron los siguientes: Testigo, Fertilización convencional, Fertilización orgánica, Fertilización convencional + solubilizadores de P y Fertilización orgánica + solubilizadores de $\mathrm{P}$.

\section{Fertilización convencional}

A partir de la fertilización convencional al suelo recomendada por el MAG (2007) y con los resultados del análisis químico inicial para el suelo con manejo convencional (Cuadro 1) que muestran la limitación de $\mathrm{N}$ y los contenidos altos de P y K, se decidió utilizar como base la dosis máxima de $200 \mathrm{~kg} \cdot \mathrm{ha}^{-1}$ de $\mathrm{N}$ y la dosis mínima de $300 \mathrm{~kg} \cdot h a^{-1}$ de $\mathrm{P}_{2} \mathrm{O}_{5}$ y de $200 \mathrm{~kg} \cdot \mathrm{ha}^{-1}$ de $\mathrm{K}_{2} \mathrm{O}$ con suelos que contienen más de la concentración necesaria de $\mathrm{P}$ y $\mathrm{K}$ para alcanzar la cosecha de papa (>50 mg. $\mathrm{l}^{-1} \mathrm{P}$ y $\left.>0,2 \mathrm{cmol}(+) . \mathrm{l}^{-1} \mathrm{~K}\right)$ y para restituir las cantidades exportadas a la planta que aumenta la eficiencia del fertilizante (Bertsch 2009). Para la fertilización convencional al suelo se utilizó urea (46-0-0) y fosfato mono potásico (P-K) (0-52-35). 
Cuadro 1. Condición química inicial del suelo con manejo orgánico y convencional en la zona de Zarcero.

\begin{tabular}{|c|c|c|c|c|c|c|c|c|c|c|c|c|}
\hline \multirow{2}{*}{ Suelo } & \multirow{2}{*}{$\begin{array}{c}\mathrm{pH} \\
\mathrm{H}_{2} \mathrm{O}\end{array}$} & \multicolumn{5}{|c|}{$\operatorname{cmol}(+) \cdot .^{-1}$} & \multirow{2}{*}{$\begin{array}{l}\% \\
\text { SA }\end{array}$} & \multicolumn{5}{|c|}{$\mathrm{mg} . \mathrm{l}^{-1}$} \\
\hline & & Acidez & $\mathrm{Ca}$ & $\mathrm{Mg}$ & $\mathrm{K}$ & CICE & & $\mathrm{P}$ & $\mathrm{Zn}$ & $\mathrm{Cu}$ & $\mathrm{Fe}$ & $\mathrm{Mn}$ \\
\hline $\mathrm{NC}^{*}$ & 5,5 & 0,5 & 4 & 1 & 0,2 & 5 & 10 & 10 & 3 & 1 & 10 & 5 \\
\hline Convencional & 5,0 & 1,40 & 4,59 & 0,58 & 1,25 & 7,82 & 18 & 350 & 4,7 & 9 & 242 & 29 \\
\hline \multirow[t]{2}{*}{ Orgánico } & 6,3 & 0,16 & 18,23 & 2,56 & 0,89 & 21,84 & 0,7 & 50 & 9,6 & 5 & 38 & 12 \\
\hline & $\% \mathrm{C}$ & \multicolumn{2}{|c|}{$\% \mathrm{~N}$} & $\mathrm{C} / \mathrm{N}$ & \multicolumn{2}{|c|}{$\% \mathrm{MO}$} & \multirow{2}{*}{$\frac{\mathrm{Ca} / \mathrm{Mg}}{2-5}$} & \multicolumn{2}{|l|}{$\mathrm{Ca} / \mathrm{K}$} & $\mathrm{Mg} / \mathrm{K}$ & \multicolumn{2}{|c|}{$\mathrm{Ca}+\mathrm{Mg} / \mathrm{K}$} \\
\hline $\mathrm{NC}^{*}$ & & \multicolumn{2}{|c|}{ oiv } & & & & & $5-25$ & & $2,5-15$ & \multicolumn{2}{|c|}{$10-40$} \\
\hline Convencional & 4,05 & \multicolumn{2}{|c|}{0,41} & 9,9 & \multicolumn{2}{|c|}{5,79} & 7,9 & 3,7 & & 0,5 & \multicolumn{2}{|c|}{4,1} \\
\hline Orgánico & 6,24 & \multicolumn{2}{|c|}{0,59} & 10,6 & \multicolumn{2}{|c|}{8,92} & 7,1 & 20,5 & & 2,9 & \multicolumn{2}{|c|}{23,4} \\
\hline
\end{tabular}

*Niveles críticos de los elementos evaluados.

Metodología de Análisis: pH en agua, acidez, Ca y $\mathrm{Mg}$ en $\mathrm{KCl}, \mathrm{P}, \mathrm{K}, \mathrm{Zn}, \mathrm{Fe}, \mathrm{Mn}$ y $\mathrm{Cu}$ en Olsen modificado; C y N totales por combustión seca en el Autoanalizador C/N. \%MO calculado a partir del \%C Total multiplicado por el factor de correlación $(1,43)$ determinado en el LSF/CIA.

Para efectuar las estimaciones de las dosis de los nutrimentos aplicados se consideró el ajuste elaborado por Moreno (2012), donde se contempla que a una densidad de siembra de 33300 plantas por hectárea, cada planta podría ocupar aproximadamente $8 \mathrm{~L}$ de suelo; este ajuste se tomó como base para llevar las dosis de kg de fertilizante.ha ${ }^{-1}$ a gramos de fertilizante por pote de $4 \mathrm{~L}$ utilizados en invernadero, como se muestra en el Cuadro 2.

Cuadro 2. Cantidades de materia prima utilizadas en la fertilización convencional para suplir las necesidades de N, P y K requeridas por el cultivo de la papa en invernadero.

\begin{tabular}{|c|c|c|c|c|c|c|}
\hline \multirow[t]{2}{*}{ Dosis } & \multicolumn{2}{|c|}{ kg.ha ${ }^{-1}$} & \multicolumn{2}{|c|}{$\begin{array}{c}\text { g.pl } \mathrm{l}^{-1} \\
\text { Volumen } 8 \mathrm{~L}\end{array}$} & \multicolumn{2}{|c|}{$\begin{array}{c}\text { g.pl-1 } \\
\text { Volumen } 4 \mathrm{~L}\end{array}$} \\
\hline & Urea $^{+}$ & $\mathrm{P}-\mathrm{K}^{*}$ & Urea & $\mathrm{P}-\mathrm{K}$ & Urea & $\mathrm{P}-\mathrm{K}$ \\
\hline Total & 435 & 577 & 13,06 & 17,33 & 6,53 & 8,66 \\
\hline Siembra & 217,5 & 346,2 & 6,53 & 10,40 & 3,27 & 5,20 \\
\hline Aporca & 217,5 & 230,8 & 6,53 & 6,93 & 3,27 & 3,46 \\
\hline
\end{tabular}

+Urea (46-0-0) *P-K: Fosfato mono potásico (0-52-35).

Estimación realizada a partir de 33300 pl.ha ${ }^{-1}$.

Además, por la deficiencia inicial de $\mathrm{Mg}$ identificada en el análisis químico (Cuadro 1) se realizó una enmienda generalizada con un producto comercial con $45 \% \mathrm{MgO}$, se calculó la dosis a partir de lo requerido en una hectárea (250 $\left.\mathrm{kg} . \mathrm{ha}^{-1}\right)$ para elevar el contenido de $\mathrm{Mg}$ al nivel óptimo (1 cmol(+). $\left.1^{-1}\right)$.

A través de la fertilización foliar con un producto comercial con $2,82 \% \mathrm{~N}, 0,5 \% \mathrm{MgO}$,
$2,8 \% \mathrm{Zn}, 1,0 \% \mathrm{Mn}, 0,25 \% \mathrm{Cu}, 0,25 \% \mathrm{Fe}, 18 \%$ aminoácidos, se suplieron los microelementos al utilizar una dosis aproximada de 1 1.ha ${ }^{-1}$ cada 2 semanas a partir de los 22 dds, que en invernadero se trató de simular con una aplicación de $1 \mathrm{ml}^{-1} \mathrm{l}^{-1}$ para las 20 plantas correspondientes a los tratamientos con fertilización convencional. 


\section{Fertilización orgánica}

Para la fertilización orgánica se utilizaron los productos elaborados y aplicados en la Finca Orgánica Guadalupe en Zarcero para la producción comercial de hortalizas.
Para el suelo se usó una mezcla de carbón de granza de arroz con biofermento a una dosis aproximada de $835 \mathrm{~kg} \cdot \mathrm{ha}^{-1}$ que corresponden a 25 $\mathrm{g}$ por pote aplicados en el punto de siembra y a la aporca. La composición total de dicho abono se observa en el Cuadro 3.

Cuadro 3. Composición química del abono orgánico sólido elaborado en la Finca Guadalupe de Zarcero para la producción de hortalizas.

\begin{tabular}{cccccccc}
\hline Componente & $\%$ & $\mathrm{~kg} \mathrm{ha}^{-1}$ & Componente & $\mathrm{mg} \cdot \mathrm{kg}^{-1}$ & $\mathrm{~kg} \cdot \mathrm{ha}^{-1}$ & Componente & \\
\hline $\mathrm{N}$ & 0,62 & 5,2 & $\mathrm{Fe}$ & 5351 & 4,50 & Humedad $(\%)$ & 29 \\
$\mathrm{P}$ & 0,49 & 4,1 & $\mathrm{Cu}$ & 25 & 0,02 & $\mathrm{pH}$ & 7,2 \\
$\mathrm{Ca}$ & 1,54 & 12,8 & $\mathrm{Zn}$ & 142 & 0,12 & $\mathrm{CE}(\mathrm{mS} / \mathrm{cm})$ & 10,9 \\
$\mathrm{Mg}$ & 0,89 & 7,4 & $\mathrm{Mn}$ & 684 & 0,57 & $\% \mathrm{C}$ & 12,8 \\
$\mathrm{~K}$ & 0,77 & 6,4 & $\mathrm{~B}$ & 20 & 0,02 & $\mathrm{C} / \mathrm{N}$ & 20,7 \\
$\mathrm{~S}$ & 0,43 & 3,6 & & & & & \\
\hline
\end{tabular}

Laboratorio de Suelos y Foliares, CIA/UCR.

Unidades expresadas en base seca $(\% \mathrm{~m} / \mathrm{m})$.

Metodología de Análisis: pH y conductividad eléctrica en agua, $\mathrm{P}, \mathrm{Ca}, \mathrm{Mg}, \mathrm{K}, \mathrm{S}, \mathrm{Fe}, \mathrm{Cu}, \mathrm{Zn}, \mathrm{Mn}$ y B por digestión húmeda con $\mathrm{HNO}_{3}$ y determinación por Espectrometría de Emisión Atómica con Plasma; C total y C/N por combustión seca en el Autoanalizador $\mathrm{C} / \mathrm{N}$.

Para la fertilización foliar orgánica se utilizó biofermento multimineral al $2 \%\left(20 \mathrm{ml}^{-\mathrm{l}^{-1}}\right)$ hecho a base de pasto fermentado combinado con biofermento de micronutrientes también elaborado en la Finca Guadalupe en Zarcero. Este biofermento se utilizó en alternancia a partir de los 22 dds con un producto orgánico con $30 \% \mathrm{Ca}, 10 \%$ B, $0,8 \%$ aminoácidos a una dosis aproximada de 2,8 kg.ha-1 (a razón de 33300 pl.ha ${ }^{-1}$ ) que en invernadero se simularon con $1,7 \mathrm{~g} .1^{-1}$ para las 20 plantas con fertilización orgánica y otro producto con $13,4 \% \mathrm{~N}, 4 \% \mathrm{~K}_{2} \mathrm{O}, 85 \%$ aminoácidos con una dosis aproximada de 2,3 kg.ha-1 a razón de 1,4 g..$^{-1}$ para las 20 plantas correspondientes en invernadero. La composición total del biofermento para cada aplicación se expone en el Cuadro 4.

Cuadro 4. Composición del biofermento foliar multimineral utilizado para la producción de hortalizas elaborado en la Finca Guadalupe de Zarcero.

\begin{tabular}{cccccc}
\hline Componente & $\%$ & Componente & mg.kg-1 & Componente & \\
\hline $\mathrm{N}$ & 1,59 & $\mathrm{Fe}$ & 2383 & $\mathrm{pH}$ & 3,7 \\
$\mathrm{P}$ & 2,19 & $\mathrm{Cu}$ & 376 & $\mathrm{CE}\left({\left.\mathrm{mS} . \mathrm{cm}^{-1}\right)}\right.$ & 65,40 \\
$\mathrm{Ca}$ & 0,02 & $\mathrm{Zn}$ & 236 & Densidad $\left(\mathrm{g} \cdot \mathrm{ml}^{-1}\right)$ & 1,15 \\
$\mathrm{Mg}$ & 0,85 & $\mathrm{Mn}$ & 817 & & \\
$\mathrm{~K}$ & 0,09 & $\mathrm{~B}$ & 177 & & \\
$\mathrm{~S}$ & 1,17 & & & & \\
\hline
\end{tabular}

Laboratorio de Suelos y Foliares, CIA/UCR.

Unidades expresadas en base seca $(\% \mathrm{~m} / \mathrm{m})$.

Metodología de Análisis: pH y conductividad eléctrica en agua, $\mathrm{P}, \mathrm{Ca}, \mathrm{Mg}, \mathrm{K}, \mathrm{S}, \mathrm{Fe}, \mathrm{Cu}, \mathrm{Zn}, \mathrm{Mn}$ y B por digestión húmeda con $\mathrm{HNO}_{3}$ y determinación por Espectrometría de Emisión Atómica con Plasma; N por digestión húmeda con ácido sulfúrico y determinación colorimétrica en el analizador de Inyección de Flujo. 


\section{Solubilizadores de $\mathbf{P}$}

La inoculación de los solubilizadores de $\mathrm{P}$ en los tratamientos que lo requirieron, se realizó con Fertibiol 45L ${ }^{\circledR}$ que es una mezcla de cepas bacterianas promotoras del crecimiento vegetal con propiedades solubilizadoras de $\mathrm{P}$ y fijadoras de $\mathrm{N}$ (Cuadro 5) formulada por el Laboratorio de Microbiología Agrícola del CIA-UCR. Esta aplicación se realizó con una dosis de $100 \mathrm{ml}$ por pote a la siembra, directamente a la semilla y se repitió a los 15 , 29 y 60 dds al suelo.

Cuadro 5. Composición microbiológica del biofertilizantebiocontrolador Fertibiol ${ }^{\circledR}$ para la inoculación de solubilizadores de P.

\begin{tabular}{lcc}
\hline \multicolumn{1}{c}{ Componente } & Cepa & UFC.ml $^{-1}$ \\
\hline Bacillus & CIA 200-201-202 & $25 \times 10^{10}$ \\
Pseudomonas & CIA 110-101 & $46 \times 10^{9}$ \\
Azotobacter & CIA 300 & $12 \times 10^{9}$ \\
\hline
\end{tabular}

Laboratorio de Microbiología Agrícola, CIA/UCR.

\section{Variables evaluadas}

Previo al establecimiento del ensayo y al final del mismo se evaluaron las siguientes características químicas: análisis químico completo que incluye $\mathrm{pH}$, acidez, $\mathrm{Ca} \mathrm{y}$ $\mathrm{Mg}$ en $\mathrm{KCl}, \mathrm{P}, \mathrm{K}, \mathrm{Zn}, \mathrm{Fe}, \mathrm{Mn}$ y $\mathrm{Cu}$, y $\mathrm{C}$ y $\mathrm{N}$ totales, \%MO. Las variables microbiológicas evaluadas fueron: el recuento de solubilizadores de $\mathrm{P}$, bacterias, hongos y actinomicetes y la determinación de la tasa de respiración del suelo.

Al final del ensayo, a los 85 dds, se evaluaron las características químicas del suelo y las variables microbiológicas y biológicas: solubilizadores de $\mathrm{P}$ y tasa de respiración, el peso fresco y seco aéreo de cada planta, número y peso fresco de tubérculos, y densidad longitudinal radicular (longitud/volumen de suelo).

\section{Evaluación de la residualidad de los sistemas de fertilización}

Luego de finalizado el ensayo con la papa, se estableció una prueba con maíz blanco híbrido para evaluar la residualidad de cada sistema de fertilización, se colocaron 50 semillas por pote y se evaluó la biomasa seca aérea producida.

\section{Análisis estadísticos}

Las medias de las características agronómicas de ambos cultivos, del suelo $(\% \mathrm{C} ; \% \mathrm{~N}$; $\mathrm{C} / \mathrm{N} ; \% \mathrm{MO}$ ) y las microbianas fueron sometidas a un análisis de comparación con el Test DGC por medio del Modelo Lineal Mixto, con el Software Estadístico INFOSTAT versión 2008.

Para la interpretación de las características químicas de los suelos, se estableció la diferencia entre la concentración inicial y la final de cada elemento, según los niveles críticos estimados por Méndez y Bertsch (2012) y las variaciones consideradas aceptables dentro de los análisis de laboratorio que se señalan en Corrales et al. (2005).

\section{RESULTADOS Y DISCUSIÓN}

\section{Características de los suelos comparados}

A nivel químico los suelos muestran diferencias importantes, como resultado del diferente manejo recibido de manera continua durante más de 20 años (Cuadro 1).

El suelo con manejo convencional muestra las características típicas de un suelo volcánico acidificado por prácticas agrícolas, con valores de acidez intercambiable mayores a $1 \mathrm{cmol}(+) . \mathrm{l}^{-1}$, y $\mathrm{pH}$ inferior a 5,5. El valor de Ca resulta normal para suelos originados de cenizas del Poás (Bertsch 1987, Henríquez et al. 2014), mientras que el Mg muestra síntomas de pérdida causada, ya sea por el uso intensivo de fertilizantes nitrogenados amoniacales (Méndez y Bertsch 2012) con efecto residual ácido que puede inducir el lavado de bases como Mg (Alvarado 2001) o por el uso de fertilizantes potásicos (Bertsch 2001), ya que 
al haber una baja concentración de $\mathrm{Mg}$ en el suelo con respecto al $\mathrm{K}$ se crea una relación antagónica en la solución del suelo, que finalmente afecta la disponibilidad de Mg para la planta (Pinilla et al. 2011). Por su parte, el K evidencia la acumulación normal que ocasiona la sobredosificación con fórmulas completas (Ramírez et al. 2014).

El suelo con manejo orgánico presenta una mayor cantidad de materia orgánica lo que concuerda con las observaciones de Mondelaers et al. 2009 y Gomiero et al. 2011. Esta mayor cantidad de materia orgánica tiene efecto regulador sobre la acidez por su tendencia a formar complejos órgano-minerales que inactivan el $\mathrm{Al}^{3+}$ en la solución del suelo (Chinchilla et al. 2011, García et al. 2011). Al ocurrir este proceso la acidez intercambiable presenta valores muy bajos (menores de 0,2 $\mathrm{cmol}(+) . \mathrm{l}^{-1}$ ) y el $\mathrm{pH}$ alcanza niveles de neutralidad (mayores a 6,0). De acuerdo con Bending (2004), el aumento del contenido de materia orgánica de un suelo está asociado directamente a un incremento de su calidad.

También se observó un considerable aumento en la CICE del suelo orgánico en comparación con el suelo convencional, pues los contenidos de Ca y $\mathrm{Mg}$ se cuadruplicaron (Cuadro 1). Este efecto se atribuye al aumento en la superficie de retención cargada negativamente que ocasiona la acumulación de coloides orgánicos (García et al. 2011).

En cuanto a relaciones de bases, las modificaciones que han sufrido especialmente el $\mathrm{Ca}$ y el $\mathrm{Mg}$ en ambos suelos hacen que en el suelo convencional se observe un desbalance en todas las relaciones, principalmente por el deficiente contenido de $\mathrm{Mg}$ con respecto al $\mathrm{Ca}$ y al $\mathrm{K}$, mientras que en el suelo con manejo orgánico el desbalance se da en la relación $\mathrm{Ca} / \mathrm{Mg}$, debido al alto contenido de Ca (Cuadro 1).

Los porcentajes de $\mathrm{C}$ y $\mathrm{N}$ totales son inferiores en el suelo convencional $(4,04 \mathrm{y}$ 0,41 respectivamente) con respecto al orgánico $(6,24$ y 0,59$)$ (Cuadro 1$)$, mientras que la relación $\mathrm{C} / \mathrm{N}$, indicador de las capacidades de mineralización de la materia orgánica presente (Ferrera y Alarcón 2001), fueron similares en ambas condiciones. El contenido de materia orgánica estimable fue $35 \%$ mayor en el suelo orgánico. Las aplicaciones de materiales orgánicos favorecen la reducción de la tasa de pérdida del $\mathrm{N}$ por una mayor estabilidad en el sistema (Tein et al. 2014, Reganold y Whatcher 2016).

El P en ambas condiciones presenta valores altos, incluso está en el límite o muy por encima del Nivel Crítico establecido para papa (Soto 2001). En el caso del suelo convencional el elevado contenido del elemento (376 mg. $\mathrm{l}^{-1}$ ) está directamente relacionado con las aplicaciones frecuentes de fertilizantes inorgánicos (Alvarado et al. 2009, Ramírez et al. 2014). Mientras que en el suelo orgánico, la alta concentración de $\mathrm{P}$ (50 mg. $\mathrm{l}^{-1}$ ) puede estar asociada a aplicaciones de fuentes minerales como roca fosfórica y al contenido alto de materia orgánica que representa un factor formador de fosfatos orgánicos (Chinchilla et al. 2011).

$\mathrm{El} \mathrm{Cu}, \mathrm{Fe}$ y $\mathrm{Mn}$ (Cuadro 1) en el suelo convencional concuerdan con valores normales encontrados en los suelos de esta región, mientras que en el suelo orgánico, aunque dentro de los rangos normales, los valores son mucho menores, especialmente para Fe y el Mn, probablemente en respuesta a la elevación del $\mathrm{pH}$ que muestra este suelo (Alvarado 2001). El Zn (Cuadro 1) está por encima del Nivel Crítico en ambas condiciones, pero es mayor en el suelo orgánico, posiblemente por la mayor adsorción que ocurre en los coloides orgánicos (Mingorance 2010).

En cuanto a las variables microbianas, la cantidad de UFC de actinomicetes y bacterias encontrada en el suelo convencional fue menor que en el suelo orgánico, en 1 y 2 órdenes de magnitud respectivamente, mientras que la tasa de respiración fue mayor en el suelo convencional, al alcanzar una diferencia de $30 \%$ entre ambos valores (Cuadro 6). Los hongos presentaron el mismo orden de magnitud de UFC en ambos suelos. 
Cuadro 6. Características microbiológicas del suelo de la zona de Zarcero con 2 manejos de producción, convencional y orgánico.

\begin{tabular}{|c|c|c|c|c|c|}
\hline \multirow[b]{2}{*}{ Suelo } & \multicolumn{4}{|c|}{ UFC. $g^{-1}$} & \multirow{2}{*}{$\begin{array}{c}\mathrm{mg} \cdot \mathrm{g}^{-1} \cdot \mathrm{dí}^{-1} \mathrm{CO}_{2} \\
\text { Tasa de } \\
\text { respiración }\end{array}$} \\
\hline & $\begin{array}{c}\text { Solubilizadores } \\
\text { de P }\end{array}$ & Actinomicetes & Bacterias & Hongos & \\
\hline Convencional & $4,0 \times 10^{5}$ & $4,7 \times 10^{6}$ & $9,5 \times 10^{6}$ & $3,2 \times 10^{5}$ & 0,247 \\
\hline Orgánico & $2,4 \times 10^{6}$ & $3,1 \times 10^{7}$ & $2,0 \times 10^{8}$ & $2,1 \times 10^{5}$ & 0,170 \\
\hline
\end{tabular}

En suelos convencionales las aplicaciones de fertilizantes inorgánicos y las actividades intensas de laboreo del suelo pueden afectar de manera diferente las poblaciones de microorganismos. Hay reportes que indican que el manejo convencional aumenta la actividad microbiana, debido a la presencia de mayor cantidad de nutrientes en la solución del suelo, mientras que otros autores señalan las repercusiones negativas sobre la diversidad de las poblaciones de microorganismos, debidas al manejo intensivo (García et al. 2011, Kibblewhite et al. 2015, Barrios 2007).

El suelo orgánico, por el manejo de conservación que recibe, puede generar un ambiente propicio para que las poblaciones microbianas se estabilicen al alcanzar poblaciones más altas y/o más diversas. Una menor tasa de respiración puede indicar una mayor eficiencia en el metabolismo y uso de nutrimentos en el suelo (Bendig et al. 2004, Martínez et al. 2008). En concordancia con esta observación, en este ensayo las cantidades de UFC en el suelo orgánico son mayores a las presentes en el suelo convencional, pero la respiración fue menor.
Mondelaers (2009) y Gomiero et al. (2011) indican que los sistemas orgánicos presentan niveles más altos de $\mathrm{C}$ orgánico, mayor aireación y retención de humedad, así como menor acidez, pérdida de nutrientes y erosión, y en general una mejor calidad del suelo comparados con los sistemas convencionales. Adicionalmente, los sistemas agrícolas orgánicos presentan una mayor diversidad microbiana.

\section{Evaluación de los suelos con el cultivo de papa}

Las modificaciones sufridas en cada tipo de suelo en respuesta a los diferentes tratamientos aplicados en el ensayo con papa, se observan en el Cuadro 7. Debido a que el experimento fue de corta duración (3 meses) y en invernadero, no se esperaba observar cambios significativos en las características químicas de los suelos, por lo que solo las concentraciones de $\mathrm{C}$ y $\mathrm{N}$ se determinaron en todas las repeticiones de los tratamientos, mientras que el resto de los elementos sólo se analizaron en una de las repeticiones para observar las tendencias. A pesar de eso, hay algunos comportamientos que son importantes de destacar. 


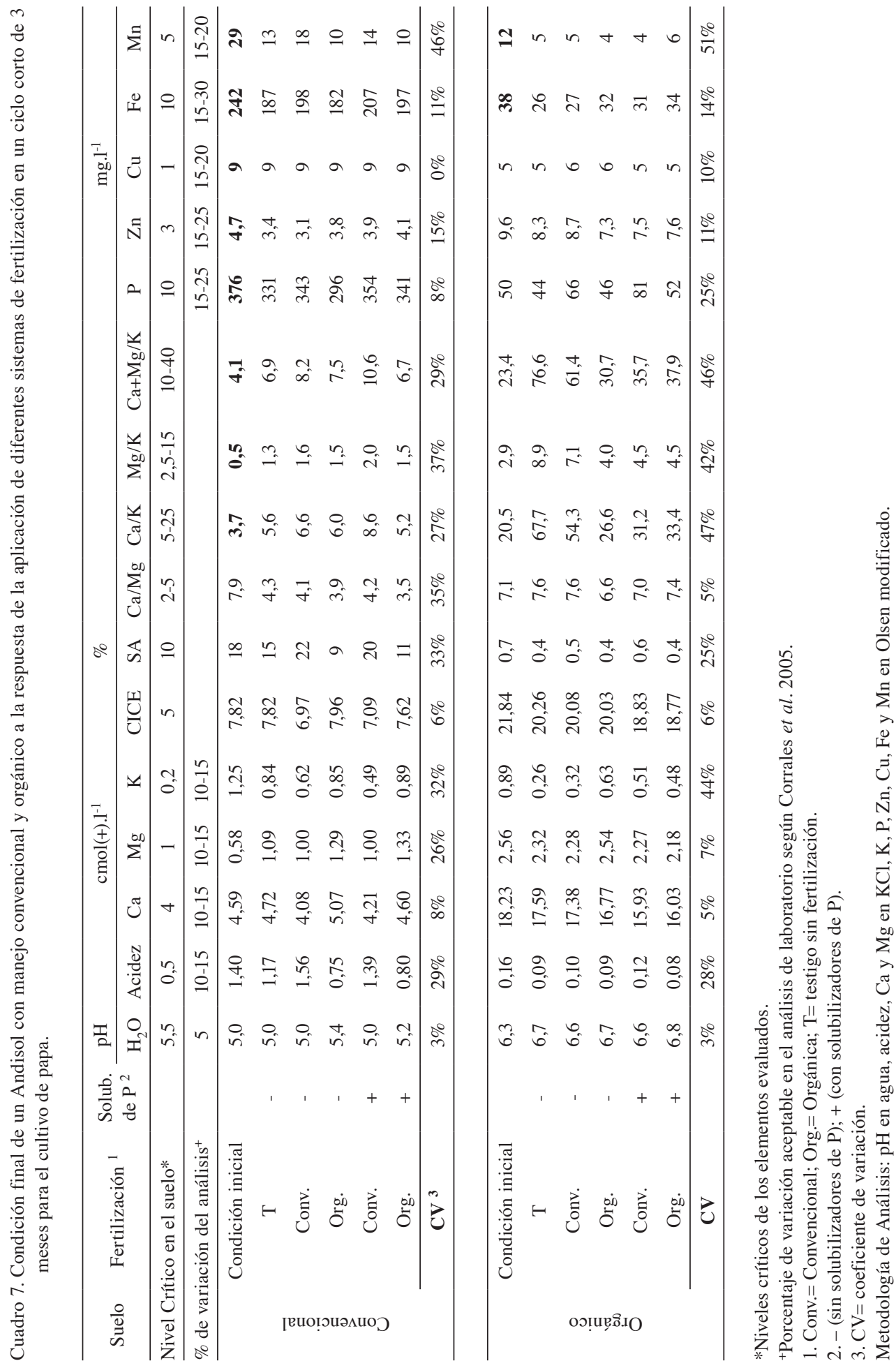


El CV (Coeficiente de Variación) incluido en el Cuadro 7, se calculó a partir de los 5 tratamientos y el valor inicial de cada elemento en cada suelo con su respectivo manejo, convencional y orgánico, con el propósito de darle más atención a aquellos elementos en los que la variación fuera superior a la aceptada como normal en los análisis de laboratorio (\% de variación del análisis) (Corrales et al. 2005). Como se observa en el Cuadro 7, en el suelo convencional, los elementos que presentaron \% de variación más altos que los establecidos (Corrales et al. 2005), fueron: la acidez, el $\mathrm{Mg}$, el $\mathrm{K}$ y el $\mathrm{Mn}$, mientras que en los tratamientos del suelo orgánico fueron la acidez, el K y el Mn.

En el caso de la acidez, aún en ese corto tiempo, en ambos suelos, los tratamientos que disminuyeron sustancialmente la cantidad de acidez intercambiable del suelo fueron los que recibieron fertilización orgánica. Este efecto se apreció también en el \%SA que disminuyó casi a la mitad y levemente en el $\mathrm{pH}$ que tendió a mostrar valores más altos en esos tratamientos. Esto confirma el papel regulador de la materia orgánica sobre la acidez de los suelos (Chinchilla et al. 2011, García et al. 2011).

Las concentraciones de $\mathrm{K}$ y $\mathrm{Mn}$ se redujeron tanto en el suelo convencional como en el orgánico (Cuadro 7). En el caso del K, este descenso podría explicarse por su alta movilidad y dinámica en el suelo, la cual es afectada por el pH del sistema (Henríquez et al. 2014), por lo que en los tratamientos en suelo convencional con $\mathrm{pH}$ menor pudo perderse de la solución del suelo por lixiviación o lavado. En el caso de los tratamientos en el suelo orgánico este descenso pudo ocurrir por la fijación de estos elementos en la estructura de la alófana (Alvarado 2001).
Las relaciones de bases en los tratamientos establecidos en suelo convencional, en general mejoraron al final del ensayo por la aplicación de Mg. En los tratamientos en suelo orgánico, el alto contenido de $\mathrm{Ca}$ en el suelo y la reducción de $\mathrm{K}$ tendieron a subir las relaciones $\mathrm{Ca}+\mathrm{Mg} / \mathrm{K}$ y $\mathrm{Ca} / \mathrm{K}$, y especialmente en los tratamientos que involucraron fertilización orgánica o solubilizadores de $\mathrm{P}$, alcanzaron valores óptimos (Cuadro 7).

Sobre el nivel de $\mathrm{P}$ no se observó un cambio sustancial en los tratamientos en suelo convencional $(\mathrm{CV}<15 \%)$. En los tratamientos del suelo orgánico, se obtuvo una variación del 25\%, debido al aumento en el tratamiento de fertilización convencional con solubilizadores de $\mathrm{P}$ que se elevó de 50 a 81 mg.t ${ }^{-1}$ (Cuadro 7).

Tanto en el suelo convencional como en el suelo orgánico, es posible observar que en los 2 tratamientos en los que se adicionaron solubilizadores de $\mathrm{P}$, la concentración de este elemento se redujo en menor magnitud en comparación con los otros 2 tratamientos que no llevaban los microorganismos (Cuadro 7). Esta tendencia se puede relacionar con la solubilización del fosfato mineral y la mineralización del P orgánico (Sánchez et al. 2014) generada por los microorganismos solubilizadores de $\mathrm{P}$ adicionados al suelo, que permitieron que el elemento se mantuviera en la solución del suelo.

En cuanto al $\% \mathrm{C}, \% \mathrm{~N}$, la relación $\mathrm{C} / \mathrm{N}$ y el \%MO de los suelos, no se observaron cambios con respecto a la condición inicial en ninguno de los 2 suelos, ya que se mantuvo la diferencia significativa encontrada al inicio entre el suelo convencional y el suelo orgánico, tal como se observa en el Cuadro 8. 
Cuadro 8. Contenido final de carbón y nitrógeno total $(\% \mathrm{C}$ y $\% \mathrm{~N})$, la relación $\mathrm{C} / \mathrm{N}$ y el contenido de materia orgánica $(\% \mathrm{MO})$ en un suelo Andisol con manejo de fertilización convencional y orgánico.

\begin{tabular}{|c|c|c|c|c|c|c|}
\hline Suelo & Fertilización ${ }^{1}$ & $\begin{array}{c}\text { Solubilizadores } \\
\text { de } \mathrm{P}^{2}\end{array}$ & $\% \mathrm{C}$ & $\% \mathrm{~N}$ & $\mathrm{C} / \mathrm{N}$ & $\% \mathrm{MO}$ \\
\hline \multirow{6}{*}{ 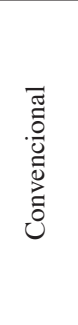 } & $\begin{array}{l}\text { Condición } \\
\text { inicial }\end{array}$ & & 4,05 & 0,41 & 9,90 & 5,79 \\
\hline & $\mathrm{T}$ & - & $4,17 \mathrm{a}$ & $0,41 \mathrm{a}$ & $10,18 \mathrm{a}$ & $5,96 \mathrm{a}$ \\
\hline & Conv. & - & $4,25 \mathrm{a}$ & $0,45 \mathrm{a}$ & 9,40 a & $6,08 \mathrm{a}$ \\
\hline & Org. & - & $4,25 \mathrm{a}$ & $0,42 \mathrm{a}$ & $10,15 \mathrm{a}$ & $6,08 \mathrm{a}$ \\
\hline & Conv. & + & $4,28 \mathrm{a}$ & $0,44 \mathrm{a}$ & 9,75 a & $6,12 \mathrm{a}$ \\
\hline & Org. & + & $4,19 \mathrm{a}$ & $0,43 \mathrm{a}$ & 9,78 a & $5,99 \mathrm{a}$ \\
\hline \multirow{6}{*}{ 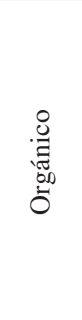 } & $\begin{array}{l}\text { Condición } \\
\text { inicial }\end{array}$ & & 6,24 & 0,59 & 10,60 & 8,92 \\
\hline & $\mathrm{T}$ & - & $6,19 \mathrm{~A}$ & $0,56 \mathrm{~A}$ & $11,00 \mathrm{~A}$ & $8,85 \mathrm{~A}$ \\
\hline & Conv. & - & $6,33 \mathrm{~A}$ & $0,59 \mathrm{~A}$ & $10,73 \mathrm{~A}$ & $9,05 \mathrm{~A}$ \\
\hline & Org. & - & $6,61 \mathrm{~A}$ & $0,60 \mathrm{~A}$ & $10,98 \mathrm{~A}$ & $9,45 \mathrm{~A}$ \\
\hline & Conv. & + & $6,50 \mathrm{~A}$ & $0,60 \mathrm{~A}$ & $10,88 \mathrm{~A}$ & $9,30 \mathrm{~A}$ \\
\hline & Org. & + & $6,42 \mathrm{~A}$ & $0,59 \mathrm{~A}$ & $10,85 \mathrm{~A}$ & $9,18 \mathrm{~A}$ \\
\hline
\end{tabular}

1. Conv.= Convencional; Org.= Orgánica; $\mathrm{T}=$ testigo sin fertilización.

2. - (sin solubilizadores de $\mathrm{P}) ;+($ con solubilizadores de $\mathrm{P})$.

Metodología de Análisis: C y N totales determinados por combustión seca en el autoanalizador C/N. \%MO calculado a partir del \%C Total multiplicado por el factor de correlación $(1,43)$ determinado en el LSF/CIA.

Medias con una letra común no son significativamente diferentes ( $p>0,05)$.

Mader et al. (2002), Tein et al. (2014) y Reganold y Whatcher (2016) han confirmado que los sistemas orgánicos presentan una fertilidad más estable que los convencionales, principalmente cuando han sido manejados varios años de esa forma, debido a la menor aplicación de insumos externos y a la incorporación de materia orgánica, esto permite que exista un alto nivel de ciclaje de los nutrimentos y por lo tanto una mayor estabilidad. Por otro lado, en los sistemas convencionales, los cultivos dependen de insumos externos adicionados al suelo en cada ciclo de cultivo y generalmente no asociados a prácticas culturales que reintegren materia orgánica al suelo (Cavigelli et al. 2008, Gliessman 2002, Leifeld et al. 2009).
En cuanto a las variables microbiológicas, al final del ensayo se contabilizó el NMP de los solubilizadores de $\mathrm{P}$ y la tasa de respiración microbiana (Cuadro 9). En el suelo convencional se observó un incremento de la cantidad NMP en todos los tratamientos de hasta 2 órdenes de magnitud (Cuadro 9). Esto podría asociarse a la alta susceptibilidad que tienen los microorganismos a los cambios abióticos y bióticos del sistema.

En el caso del suelo orgánico donde probablemente se presentan poblaciones microbianas con una estabilidad mayor, los recuentos fueron similares entre el suelo inicial y el final, sin embargo, la adición de microorganismos solubilizadores de P combinada con la aplicación de fertilización orgánica afectó negativamente las poblaciones de solubilizadores de $\mathrm{P}$. 
Cuadro 9. Características microbiológicas de un suelo con sistemas de fertilización convencional y orgánica establecidos en potes en invernadero después de 3 meses con el cultivo de papa.

\begin{tabular}{|c|c|c|c|c|}
\hline Suelo & Fertilización ${ }^{1}$ & $\begin{array}{l}\text { Solub. } \\
\text { de } \mathrm{P}^{2}\end{array}$ & $\begin{array}{c}\text { NMP g-1 }^{-1} \\
\text { Solubilizadores de P }\end{array}$ & $\begin{array}{l}\mathrm{mg} \cdot \mathrm{g}^{-1} \cdot \mathrm{dí}^{-1} \mathrm{CO}_{2} \\
\text { Tasa de respiración }\end{array}$ \\
\hline \multirow{6}{*}{ 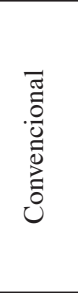 } & Condición inicial & & $4,00 \times 10^{5}$ & 0,247 \\
\hline & $\mathrm{T}$ & - & $4,02 \times 10^{7} \mathrm{a}$ & $0,050 \mathrm{c}$ \\
\hline & Conv. & - & $3,10 \times 10^{6} \mathrm{~b}$ & $0,370 \mathrm{~b}$ \\
\hline & Org. & - & $2,44 \times 10^{7} \mathrm{a}$ & $0,050 \mathrm{c}$ \\
\hline & Conv. & + & $7,77 \times 10^{6} \mathrm{a}$ & $0,370 \mathrm{~b}$ \\
\hline & Org. & + & $1,57 \times 10^{7} \mathrm{a}$ & $0,620 \mathrm{a}$ \\
\hline \multirow{6}{*}{ 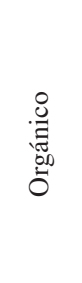 } & Condición inicial & & $2,40 \times 10^{6}$ & 0,170 \\
\hline & $\mathrm{T}$ & - & $4,94 \times 10^{6} \mathrm{~A}$ & $0,620 \mathrm{~A}$ \\
\hline & Conv. & - & $1,78 \times 10^{7} \mathrm{~A}$ & $0,500 \mathrm{~B}$ \\
\hline & Org. & - & $1,56 \times 10^{7} \mathrm{~A}$ & $0,560 \mathrm{~A}$ \\
\hline & Conv. & + & $1,55 \times 10^{6} \mathrm{~B}$ & $0,440 \mathrm{~B}$ \\
\hline & Org. & + & $2,20 \times 10^{4} \mathrm{~B}$ & $0,500 \mathrm{~B}$ \\
\hline
\end{tabular}

1. Conv.= Convencional; Org.= Orgánica; $\mathrm{T}=$ testigo sin fertilización.

2. - (sin solubilizadores de P); + (con solubilizadores de P).

Medias con una letra común no son significativamente diferentes ( $p>0,05)$.

En el caso de la tasa de respiración es destacable la magnitud con la que se incrementó en ambos suelos y en la mayoría de los tratamientos con respecto a la condición inicial (Cuadro 9), este aumento fue mayor y menos errático en el suelo de manejo orgánico. En un suelo orgánico, como el del presente ensayo, es de esperar que se presente una mayor actividad microbiológica al ser sometido a cualquier tipo de disturbio, ya que presenta una alta población de microorganismos y una mayor cantidad de materia orgánica disponible para los microorganismos (Ferrera y Alarcón 2001).

\section{Variables evaluadas en cultivo de papa}

En el Cuadro 10 se muestran los datos de la evaluación del efecto del manejo de suelo y de fertilización sobre el desarrollo y el rendimiento del cultivo de la papa. 
Cuadro 10. Desarrollo aéreo, radical y rendimiento de tubérculos de las plantas de papa cultivadas en potes en invernadero bajo sistemas de fertilización en un suelo con manejo convencional y orgánico.

\begin{tabular}{|c|c|c|c|c|c|c|}
\hline Suelo & Fertilización ${ }^{1}$ & $\begin{array}{l}\text { Solub. } \\
\text { de } \mathrm{P}^{2}\end{array}$ & $\begin{array}{c}\text { Biomasa } \\
\text { aérea seca }(\mathrm{g})\end{array}$ & $\begin{array}{l}\text { Cantidad de } \\
\text { tubérculos }\end{array}$ & $\begin{array}{l}\text { Rendimiento } \\
\text { (Peso fresco de } \\
\text { tubérculos g) }\end{array}$ & $\begin{array}{c}\text { Densidad } \\
\text { Radical } \\
\left(\mathrm{cm} / \mathrm{cm}^{3}\right)\end{array}$ \\
\hline \multirow{5}{*}{ 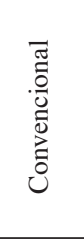 } & $\mathrm{T}$ & - & $3,88 \mathrm{~b}$ & $15 \mathrm{~b}$ & $96 \mathrm{~b}$ & $7,75 \mathrm{~b}$ \\
\hline & Conv. & - & $20,03 \mathrm{a}$ & $20 \mathrm{a}$ & $123 \mathrm{~b}$ & $8,83 \mathrm{a}$ \\
\hline & Org. & - & $4,17 \mathrm{~b}$ & $14 \mathrm{~b}$ & $97 \mathrm{~b}$ & $6,65 \mathrm{~b}$ \\
\hline & Conv. & + & $19,92 \mathrm{a}$ & $23 \mathrm{a}$ & $164 \mathrm{a}$ & $9,35 \mathrm{a}$ \\
\hline & Org. & + & $4,70 \mathrm{~b}$ & $14 \mathrm{~b}$ & $92 \mathrm{~b}$ & $7,90 \mathrm{~b}$ \\
\hline \multirow{5}{*}{ 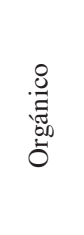 } & $\mathrm{T}$ & - & $6,42 \mathrm{~B}$ & $15 \mathrm{~B}$ & $106 \mathrm{~B}$ & $9,00 \mathrm{~A}$ \\
\hline & Conv. & - & $22,85 \mathrm{~A}$ & $12 \mathrm{~B}$ & $129 \mathrm{~A}$ & $8,13 \mathrm{~B}$ \\
\hline & Org. & - & $10,32 \mathrm{~B}$ & $13 \mathrm{~B}$ & $118 \mathrm{~A}$ & $7,70 \mathrm{~B}$ \\
\hline & Conv. & + & $19,72 \mathrm{~A}$ & $14 \mathrm{~B}$ & $126 \mathrm{~A}$ & $9,20 \mathrm{~A}$ \\
\hline & Org. & + & $5,46 \mathrm{~B}$ & $16 \mathrm{~A}$ & $106 \mathrm{~B}$ & $7,20 \mathrm{~B}$ \\
\hline
\end{tabular}

1. Conv.= Convencional; Org.= Orgánica; $\mathrm{T}=$ testigo sin fertilización.

2. - (sin solubilizadores de P); + (con solubilizadores de P).

Medias con una letra común no son significativamente diferentes ( $\mathrm{p}>0,05)$.

A nivel general para ambos suelos se obtuvo una mayor cantidad de biomasa aérea seca cuando se aplicó fertilización convencional. En el caso del rendimiento (peso fresco de tubérculos) (Figura 1), para el suelo orgánico no se encontró diferencia entre el tratamiento con fertilización

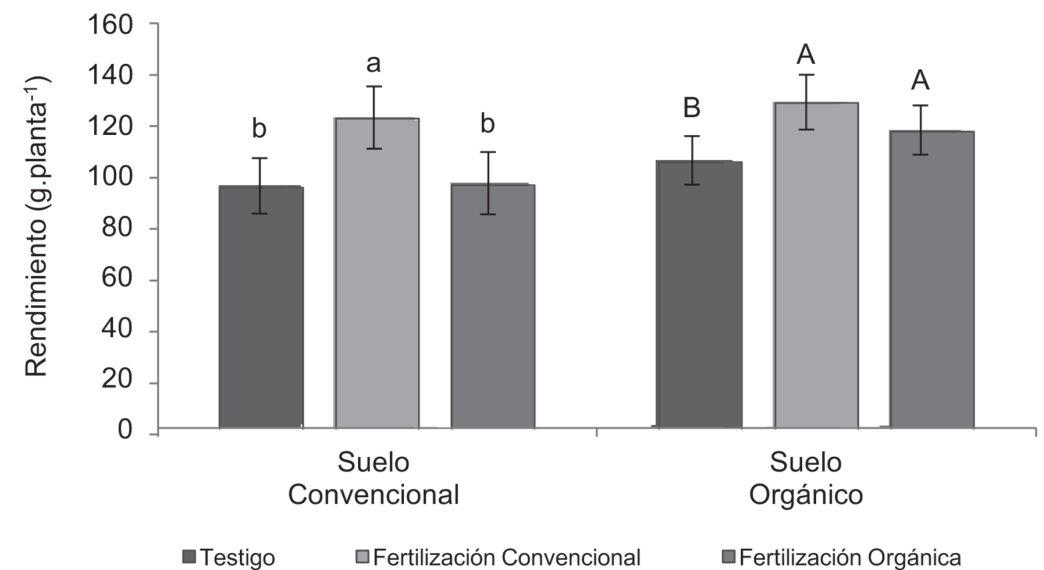

Medias con una letra común no son significativamente diferentes ( $p>0,05)$. Barras de error corresponden a la comparación general de datos.

Fig. 1. Efecto de la fertilización convencional y orgánica en un suelo con manejo convencional y orgánico sobre la producción de papa. 
convencional y con fertilización orgánica. En el caso del suelo convencional, la fertilización orgánica logró igualar al testigo sin fertilización. Esto evidencia el proceso de adaptación o "período de transición" (Soto y Descamps 2011) que requiere un suelo con manejo convencional para alcanzar altos rendimientos cuando se inician prácticas de fertilización orgánica. Para el suelo con manejo orgánico, ampliamente estabilizado (durante más de 20 años), la aplicación de una fertilización orgánica igualó los rendimientos alcanzados con la fertilización convencional en el suelo convencional (Figura 1).

Al comparar la cantidad de nutrientes adicionados con cada sistema de fertilización (Cuadro 11) y el rendimiento alcanzado (Figura 1), es notable que en el suelo con manejo orgánico, la fertilización orgánica permitió una mejor eficiencia en el uso de los nutrimentos por parte del cultivo, ya que la cantidad agregada en este caso es mínima, comparada con la cantidad de nutrientes adicionados con la fertilización convencional. Este comportamiento en el rendimiento de la papa se puede atribuir a los beneficios que aporta la materia orgánica, ya que permite una liberación gradual de los nutrimentos en la solución del suelo (Muñoz y Lucero 2008), se comprueba así, que el ciclaje nutricional en un sistema orgánico estabilizado física, química y microbiológicamente va a favorecer el rendimiento de los cultivos, en este caso, de la papa (Soto 2001, Angoa 2012, Mena 2012, Tein et al. 2014).

Cuadro 11. Composición química de la fertilización convencional y orgánica aplicada al suelo para manejos agrícolas, convencional y orgánico.

\begin{tabular}{cccccc}
\hline \multirow{2}{*}{ Fertilización } & Insumo aplicado & $\begin{array}{c}\text { Dosis usada } \\
\mathrm{kg}^{2} \mathrm{ha}^{-1}\end{array}$ & $\mathrm{~N}$ & \multicolumn{2}{c}{ Concentración kg.ha $^{-1}$} \\
\hline \multirow{2}{*}{ Convencional } & $46-0-0$ & 435 & 200 & 0 & $\mathrm{P}$ \\
Orgánico & $0-52-35$ & 577 & 0 & 132 & 168 \\
\hline
\end{tabular}

En cuanto a la adición de solubilizadores de $\mathrm{P}$, al agregarlos a la fertilización orgánica en los 2 tipos de suelo, apenas se logró el mismo resultado obtenido para los testigos (Figura 2). Sin embargo, hay que destacar el efecto positivo en el rendimiento, al combinarse con la fertilización convencional en ambos suelos (Cuadro 10 y Figura 3A) (Sánchez et al. 2014, Covarrubias et al. 2005). Se ha observado que ante la presencia de microorganismos puede ocurrir la producción de sustancias promotoras del crecimiento vegetal, la fijación de $\mathrm{N}$ y también la solubilización de $\mathrm{P}$ en el suelo (Richardson et al. 2009). 


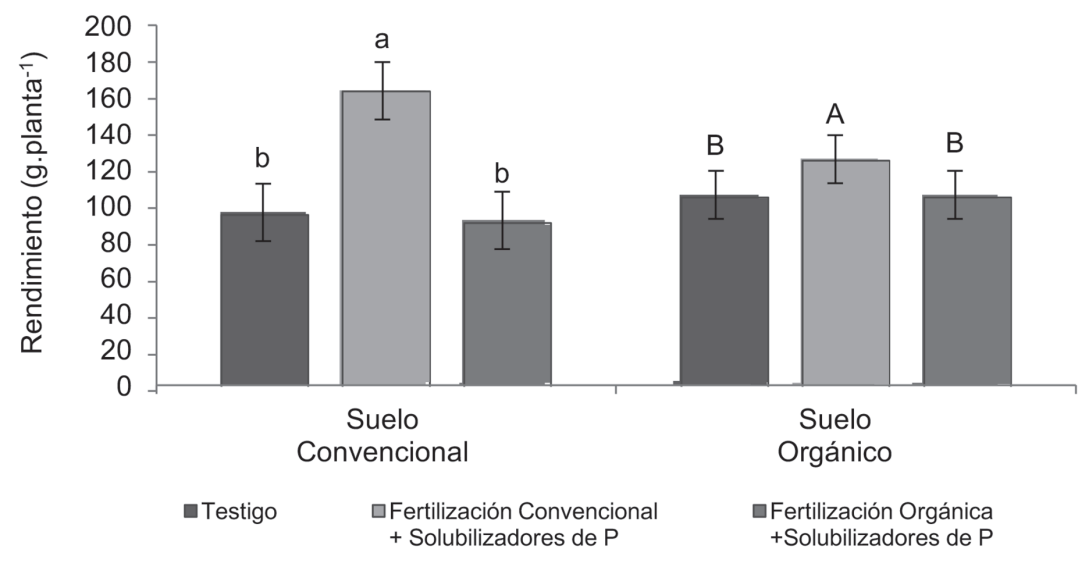

Medias con una letra común no son significativamente diferentes $(\mathrm{p}>0,05)$. Barras de error corresponden a la comparación general de datos.

Fig. 2. Efecto de la fertilización convencional y orgánica en combinación con solubilizadores de P en un suelo con manejo convencional y orgánico sobre la producción de papa.
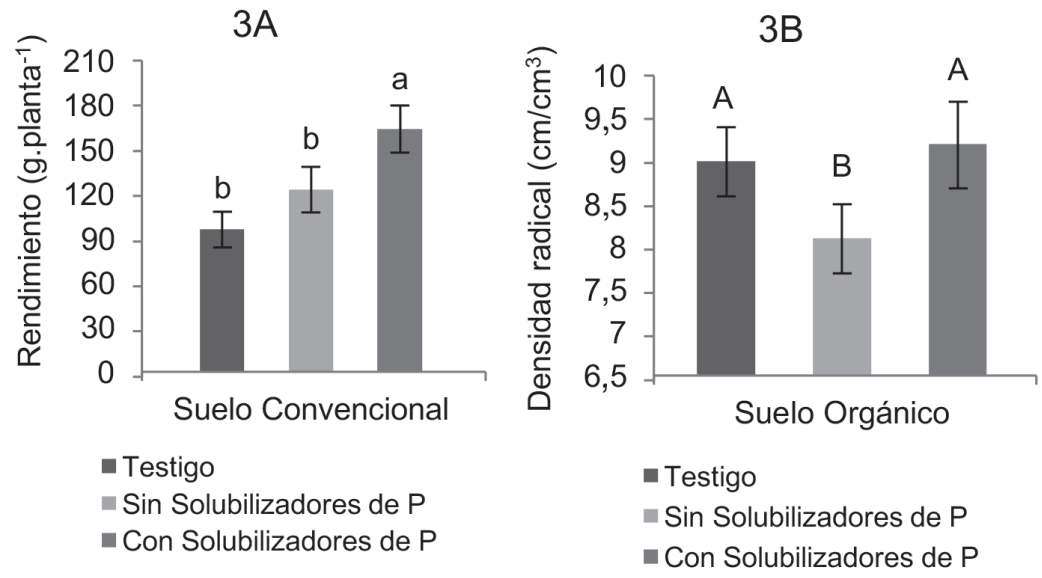

Medias con una letra común no son significativamente diferentes ( $\mathrm{p}>0,05)$.

Fig. 3. Efecto de la fertilización convencional y de la adición de solubilizadores de $\mathrm{P}$ sobre el rendimiento (3A) en peso fresco de tubérculos y en la densidad radical (3B) de la papa.

En el suelo con manejo orgánico y fertilización convencional el efecto de la aplicación de solubilizadores de $\mathrm{P}$ no se refleja en el rendimiento, sino que se expresa a nivel de la densidad de raíces (Figura 3B). No obstante, este aumento en la densidad radical en el tratamiento de fertilización convencional con solubilizadores de $\mathrm{P}$ en el suelo orgánico, no llega a superar estadísticamente al testigo en cuanto al rendimiento, por lo que pareciera que las bacterias inoculadas no logran 
desplazar a la población microbiana nativa y no se obtienen mayores ventajas, en cuanto al rendimiento, por agregar estos microorganismos en el suelo orgánico (Cuadro 10).

Según los datos de la presente investigación, el uso de inoculantes a base de solubilizadores de $\mathrm{P}$ puede mejorar el rendimiento en un sistema de fertilización convencional, mientras que en un sistema orgánico con una alta estabilidad en aspectos físicos, químicos y biológicos alcanzada por el manejo a largo plazo, su aplicación podría ser una práctica menos promisoria, ya que el suelo cuenta con una población microbiana muy establecida.

Al comparar la residualidad de la fertilización convencional frente a la orgánica en ambos suelos (Figura 4), se observa que la convencional genera mayor desarrollo vegetal del maíz. Sin embargo, el testigo del suelo orgánico produjo una mayor biomasa aérea seca comparada con la del testigo en el suelo convencional, lo que hace suponer que el testigo orgánico conserva un mayor potencial de producción.

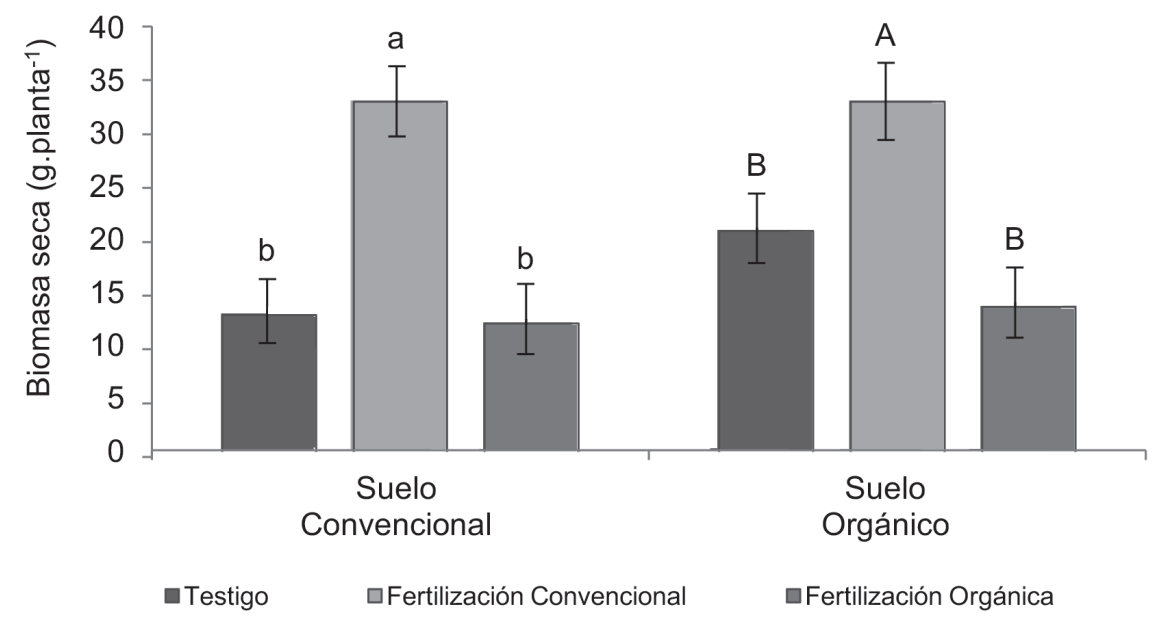

Medias con una letra común no son significativamente diferentes ( $>00,05)$. Barras de error corresponden a la comparación general de datos.

Fig. 4. Efecto residual en el suelo, por fertilización convencional y orgánica sobre el desarrollo del maíz en un suelo con manejo convencional y orgánico.

Desde el punto de vista ambiental la residualidad de la fertilización convencional puede generar efectos que reduzcan la calidad del suelo a mediano y largo plazo con consecuencias adversas al sistema edáfico y al ambiente en general (Diacono y Montemurro 2010).

Según Reganold y Wachter (2016), basados en un meta análisis de investigaciones realizadas sobre el tema, los sistemas orgánicos podrían presentar rendimientos menores en comparación con la agricultura convencional. Sin embargo, son más rentables, ambientalmente amigables y producen alimentos iguales o más nutritivos que no contienen o contienen menos residuos de plaguicidas. Además, los autores indican que los sistemas agrícolas orgánicos proporcionan mayores servicios ecosistémicos y beneficios sociales, por lo que tiene un alto potencial para el establecimiento de sistemas agrícolas sostenibles. 


\section{AGRADECIMIENTOS}

Especialmente al equipo humano de la Finca Orgánica Guadalupe, ubicada en Zarcero, Costa Rica, por toda su colaboración y a los Laboratorios de Suelos y Foliares y Microbiología Agrícola del Centro de Investigaciones Agronómicas de la Universidad de Costa Rica por el financiamiento para realizar los análisis.

\section{LITERATURA CITADA}

Alvarado, A. 2001. Manejo de suelos derivados de cenizas volcánicas. In G. Meléndez y E. Molina (eds.). Fertilidad de suelos y manejo de la nutrición de cultivos en Costa Rica, 2001, Laboratorio de Suelos y Foliares, CIA/UCR, San José, Costa Rica. p. 11-26.

Alvarado, A; Iturriaga, I; Smyth JT; Portuguez, E; Ureña, JM. 2009. Efecto residual del fertilizante fosfatado adicionado al cultivo de la papa en un Andisol de Juan Viñas, Costa Rica. Agronomía Costarricense 33(1):63-76.

Angoa, MV. 2012. Microorganismos nativos y sus beneficios en la producción agrícola. In VII Congreso Nacional de Suelos, 2012, San José, Costa Rica. 4 p.

Babilonia, R. 2011. Impactos del cambio climático en la distribución espacial de las zonas de aptitud potencial del cultivo de la papa (Solanum tuberosum) en la cuenca del río Reventazón, Costa Rica. Tesis M.Sc. CATIE, Turrialba, Costa Rica. ACCS. 151 p.

Barrios, E. 2007. Soil biota, ecosystem services and land productivity. Ecological economics 64:269-285.

Bending, G; Turnera, M; Raynsb, F; Marxc, M; Wood, M. 2004. Microbial and biochemical soil quality indicators and their potential for differentiating areas under contrasting agricultural management regimes. Soil Biology \& Biochemistry 36:1785-1792.

Bertsch, F. 1987. Manual para interpretar la fertilidad de los suelos de Costa Rica. 2 ed. Oficina de Publicaciones de la Universidad de Costa Rica, San José, Costa Rica. 76 p.

Bertsch, F. 2001. Problemas de fertilidad de suelos de Costa Rica. In Meléndez, G; Molina, E (eds.). Fertilidad de suelos y manejo de la nutrición de cultivos en Costa Rica, 2001. San José, Costa Rica, Laboratorio de Suelos y Foliares, CIA/UCR. p. 1-10.

Bertsch, F. 2009. Absorción de nutrimentos por los cultivos (multimedia). San José, Costa Rica, ACCS. p. 184-185.
Castro, L; Murillo, M; Uribe, L; Mata, R. 2015. Inoculación al suelo con Pseudomonas fluorescens, Azospirillum oryzae, Bacillus subtilis y microorganismos de montaña (MM) y su efecto sobre un sistema de rotación soya-tomate bajo condiciones de invernadero. Agronomía Costarricense 39(3):21-36.

Cavigelli, MA; Teasdale, JR; Conklin, AE. 2008. Long-term agronomic performance of organic and conventional field crops in the Mid-Atlantic Region. Agronomy Journal 100(3):785-794.

Chinchilla, M; Mata, R; Alvarado, A. 2011. Andisoles, Inceptisoles y Entisoles de la subcuenca del río Pirrís, Región de los Santos, Talamanca, Costa Rica Agronomía Costarricense 35(1):83-107.

Corrales, M; Bertsch, F; Bejarano, JA. 2005. Los laboratorios de análisis de suelos y foliares en Costa Rica: Informe del comité de laboratorios de análisis de suelos, plantas y aguas. Agronomía Costarricense 29(3):125-135.

Covarrubias, JM; Castillo, S; Vera, JA; Núñez; R; Sánchez, P; Aveldaño, R; Peña, JJ. 2005. Absorción y eficiencia de uso de fósforo en papa cultivar Alpha con ${ }^{32} \mathrm{P}$. Agrociencia 39:127-136.

Diacono, M; Montemurro, F. 2010. Long-term effects of organic amendments on soil fertility. A review. Agron. Sustain. Dev. 30:401-422.

Enríquez, F; Bernal, G. 2008. Evaluación de la efectividad de cuatro dosis de micorrizas arbusculares bajo cuatro niveles de fósforo en vivero de palmito (Bactris gasipaes, HBK), en la zona de Santo Domingo de los Colorados. In XI Congreso Ecuatoriano de la Ciencias del Suelo, 2008. Sociedad Ecuatoriana de la Ciencia del Suelo, Quito, Ecuador. 15 p.

Fernández, K; Fernández, F; Rivera, R; Olalde, V. 2010 Micorrización in vitro e in vivo de plántulas de papa (Solanum tuberosum var. Alfa). Cultivos Tropicales 31(2):21-31

Ferrera, R; Alarcón, A. 2001. La microbiología del suelo en la agricultura sostenible. Ciencia Ergo Sum. 8(2):175-183.

García, D; Mamani, G; Román, N; Suárez, L; Contreras, A; Malca, J. 2011. Efecto de la adición de materia orgánica sobre la dinámica poblacional bacteriana del suelo en cultivos de papa y maíz. Peruana de Biología 18(3):355-360.

GFA (Consulting Group S.A.). 2010. Estudio del estado de la producción sostenible y propuesta de mecanismos permanentes para el fomento de la producción sostenible. Consultoría SP-12-2009, Elaborado para el Ministerio de Agricultura y Ganadería, Costa Rica. 311 p.

Gliessman, SR. 2002. Agroecología: procesos ecológicos en agricultura sostenible. CATIE, Turrialba, Costa Rica. 359 p. 
Gomiero, T; PImentel, D; Paoletti, MG. 2011. Environmental impact of different agricultural management practices: conventional vs. organic agriculture. Crit. Rev. Plant Sci. 30:95-124.

Henríquez, C; Cabalceta, G; Bertsch, F; Alvarado, A. 2014. Principales suelos de Costa Rica (en línea). ACCS, Biblioteca Virtual de Ciencia y Producción Vegetal, MAG. Consultado 24 abr. 2015. Disponible en http://www.mag.go.cr/bibioteca_virtual_ciencia/ suelos-cr.html

Hernández, A. 2001. Manejo agronómico integral de sustratos, métodos de siembra y biofertilización en la producción sostenible de tubérculos-semilla de papa por semilla sexual. Cultivos Tropicales 22(2):21-27.

Jenkinson, D; Powlson, D. 1976. The effects of biocidal treatment on metabolism in soil-V. A method for measuring soil biomass. Soil Biology and Biochemistry 8(3):209-213.

Kibblewhite, M; Ritz, K; Swift, M. 2015. Soil health in agricultural systems. Philosophical Transactions of the Royal Society B: Biological Sciences 363(1492):685-701.

Leifeld, J., Reiser, R., OBerholzer, HR. 2009. Consequences of conventional versus organic farming on soil carbon: results from a 27-years field experiment. Agronomy Journal 101(5):1204-1218.

Mader, P; Fliebbach, A; Dubois, D; Gunst, L; Fried, P; Niggli, U. 2002. Soil Fertility and Biodiversity in Organic Farming. Science 296:1694-1697.

MAG (Ministerio de Agricultura y Ganadería). 2007. Caracterización de la agrocadena de papa, Cartago, Costa Rica. MAG, Dirección Central Oriental, Cartago, Costa Rica. 61 p.

Martínez, E; Fuentes, JP; Acevedo, E. 2008. Carbono orgánico y propiedades del suelo. Ciencia del Suelo y Nutrición Vegetal 8(1):68-96.

Mena, HG. 2012. Microorganismos riszosféricos como promotores de la calidad de productos agrícolas. In VII Congreso Nacional de Suelos, 2012, ACCS, San José, Costa Rica. 6 p.

Méndez, JC; Bertsch, F. 2012. Guía para la interpretación de la fertilidad de los suelos de Costa Rica. ACCS, San José, Costa Rica. 108 p.

Mingorance, MD. 2010. El suelo, regulador fisicoquímico de elementos traza para las plantas. Departamento Geoquímica Ambiental, Estación Experimental del Zaidín, CSIC, Granada, España. 14 p.

Monreal, M. 2003. Actividad de los microorganismos del suelo en sistemas agrícolas con uso mínimo de insumos. In Congreso Alianza Tecnológica para la Agricultura con Calidad, Memoria, 2003, San José, Costa Rica. 75 p.

Mondelaers, K., Aertsens, J; Van Huylenbroeck, G. 2009. A meta-analysis of the differences in environmental impacts between organic and conventional farming Brit. Food. J. 111:1098-1119.

Moreno, E. 2012. Efecto de la cianamida cálcica y los fosfitos como fuentes de fertilizante y sobre el tizón tardío (Phytophthora infestans) en dos variedades de papa (Solanum tuberosum) a nivel de invernadero. Tesis de Lic. San José, Costa Rica. Universidad de Costa Rica, 66 p.

Moreno, P. 1988. Inoculación de micorrizas MVA en papa (Solanum tuberosum) respuesta en el crecimiento y nutrición de plantas inoculadas en invernadero y en campo. Latinoamericana de la Papa 1:84-103.

Muñoz, LA; Lucero, AM. 2008. Efecto de la fertilización orgánica en el cultivo de papa criolla Solanum phureja. Agronomía Colombiana 26(2):340-346.

Osorio, N; Habte, M. 2001. Synergistic influence of an arbuscular mycorrhizal fungus and a $\mathrm{P}$ solubilizing fungus on growth and $\mathrm{P}$ uptake of Leucaena leucocephala in a Oxisol. Arid Land Research and Management. 15:263-274.

Pinilla, H; Herrera, L; Benavente, R; Sanhueza, H. 2011. Efecto del magnesio en el rendimiento y contenido de gluten en trigo (Triticum aestivum L.) en un suelo Andisol. IDESIA (Chile) 29(2):53-57.

Ramírez, F; Fournier, ML; Ruepert, C; Hidalgo, C. 2014. Uso de agroquímicos en el cultivo de papa en Pacayas, Cartago, Costa Rica. Agronomía Mesoamericana 25(2):337-345.

Richardson, AE: Barea, JM; Mcneill, AM; Prigent-Combaret C. 2009. Adquisition of phosphorus and nitrogen in the rizosphere and plant growth promotion by microorganisms. Plant Soil 321:305-339.

Reganold, J; Wachter, J. 2016. Organic agriculture in the twenty-first century. Nature Plants. 2:1-8.

Rojas, K; Ortuño, N. 2007. Evaluación de micorrizas arbusculares en interacción con abonos orgánicos como coadyuvantes del crecimiento en la producción hortícola del Valle Alto de Cochabamba, Bolivia (en línea). Acta Nova 3(4):697-719. Consultado 15 feb. 2014. Disponible en http://www. revistasbolivianas.org.bo/scielo.php?pid=S168307892007000200005\&script=sci_arttext

Sánchez, DB; García, AM; Romero, FA; Bonilla, RR. 2014. Efecto de rizobacterias promotoras de crecimiento vegetal solubilizadoras de fosfato en Lactuca sativa cultivar White Boston. Colombiana de Biotecnología 16(2):122-128.

SEPSA (Secretaría Ejecutiva de Planificación Sectorial Agropecuaria). 2011. Boletín Estadístico Agropecuario $\mathrm{N}^{\circ}$. 21. Área de Estadística Económicas e Información. SEPSA, San José, Costa Rica. p. 34.

Soto, G. 2001. Abonos orgánicos, producción y uso de compost. In Meléndez, G; Molina, E (eds.). Fertilidad de suelos y manejo de la nutrición de cultivos en 
Costa Rica, 2001, Laboratorio de Suelos y Foliares, CIA/UCR, San José, Costa Rica. p. 45-63.

Soto, G; Descamps, P. 2011. Certificación orgánica paso a paso: manual para familias productoras. Materiales de Extensión $N^{\circ}$. 7. CATIE, Turrialba, Costa Rica. p. 2.

Suárez, L; Giletto, C; Rattín, J; Echeverría, H; Caldiz, D. 2006. Efecto del nitrógeno sobre el rendimiento y la calidad de tubérculos en papa para industria. In XX
Congreso Argentino de la Ciencia del Suelo, 2006. INPOFOS Informaciones Agronómicas 32:19-21.

Tein, B; Kauer, K; Eremeev, V; Luik, A; Selge, A; Loit, E. 2014. Farming systems affect potato (Solanum tuberosum) tuber and soil quality. Field Crops Research 156:1-11.

Zamora, F; Tua, D; Torres, D. 2008. Evaluación de cinco fuentes orgánicas sobre el desarrollo vegetativo y rendimiento del cultivo de papa. Agronomía Tropical 58(3):233-243. 